\title{
Constructing statistical models for arch dam deformation
}

\author{
Juan Mata $^{1, * \dagger}$, António Tavares de Castro ${ }^{1}$ and José Sá da Costa ${ }^{2}$ \\ ${ }^{1}$ Monitoring Division, Concrete Dams Department, National Laboratory for Civil Engineering, Av. do Brasil 101, 1700-066, \\ Lisbon, Portugal \\ ${ }^{2}$ IST, Technical University of Lisbon, Av. Rovisco Pais 1, 1049-001, Lisbon, Portugal
}

\begin{abstract}
In its lifetime, a dam can be exposed to significant water level variations and seasonal environmental temperature changes. The structural safety control of a concrete dam is supported by monitoring activities and is based on models.

In practice, the interpretation of recorded concrete dam displacements is usually based on HST (hydrostatic, seasonal, time) statistical models. These models are widely used and consider that the thermal effect can be represented by a seasonal function. The main purpose of this paper is to present an HTT (hydrostatic, thermal, time) statistical model to interpret recorded concrete dam displacements. The idea is to replace the seasonal function with the use of recorded temperatures that better represent the thermal effect on dam behavior. Two new methodologies are presented for constructing HTT statistical models, both based on principal component analysis applied to recorded temperatures in the concrete dam body. In the first method, principal component analysis is used to choose the thermometers for the construction of the HTT model. In the second method, the thermal effect is represented by the principal components of temperature of selected thermometers.

The advantage of these methods is that the thermal effect is represented by real temperature measured in the concrete dam body. The HTT statistical models proposed are applied to the $110 \mathrm{~m}$ high Alto Lindoso arch dam, and the results are compared with the HST displacement model. Copyright (C) 2013 John Wiley \& Sons, Ltd.
\end{abstract}

Received 30 July 2012; Revised 28 February 2013; Accepted 26 March 2013

KEY WORDS: structural safety control; concrete dam behavior; thermal effect; principal component analysis; quantitative interpretation model

\section{INTRODUCTION}

The safety control of a concrete dam requires a wide range of important information coming from the monitoring system and from visual inspections [1,2]. The activities of safety control must allow for the timely detection of any anomalous dam behavior, which could deteriorate the dam, in order to implement corrective measures [3-6].

A concrete dam in normal service is permanently subjected to thermal load and hydrostatic load due to the reservoir water exploitation. Thermal load can have internal and external origins. The internal load includes the hydration heat, whereas the external loads are produced by solar radiation, air, and reservoir temperatures [7-9]. Figure 1 describes the heat transfer processes occurring in a dam-foundation-reservoir system. The temperature gradient near the exposed surface of the dam generates tensile stresses, which can cause surface cracks. These do not affect the stability of the dam, but may allow water penetration into cracks, and can originate damage by freezing and thawing [10].

Many methods have been proposed to estimate the temperature in a concrete dam during normal operation using analytical equations [10-13]. The study carried out in the investigation of the

*Correspondence to: Juan Mata, Monitoring Division, Concrete Dams Department, National Laboratory for Civil Engineering, Av. do Brasil 101, 1700-066, Lisbon, Portugal.

†E-mail: jmata@lnec.pt 